\title{
Caverno-saphenous shunt in the treatment of priapism
}

\author{
F. N. IHEKWABA \\ F.R.C.S.
}

\author{
J. LAWANI \\ F.R.C.S.
}

The Department of Surgery, University College Hospital, Ibadan, Nigeria

\section{Summary}

The painful pathological condition of the penis, priapism, is usually associated with serious destructive changes which lead to impotence if treatment is withheld or delayed. Conservative therapy is slow, uncertain and usually ineffective. Early surgical decompression of the corpora cavernosa, repeated if necessary, is essential if impotence is to be averted. Two unusual cases of this condition recently seen at the University College Hospital, Ibadan, in which treatment had been delayed for periods previously thought to be too long for recovery are herein presented and the management described. It is advised that failure of the initial surgical operation calls for early re-operation to establish a new shunt.

\section{Introduction}

Priapism is defined as a painful pathologically sustained erection of the penis unrelated to sexual stimulation or desire. The term is derived from the ancient Greco-Roman god of fertility and harvest, Priapus. It is a surgical emergency, affecting mostly the under-40 age group. Its cause is obscure. When prolonged, detumescence to the normal condition is rare. If treatment is withheld or delayed, impotence is the rule. Conservative therapy is slow, uncertain and usually ineffective. Emergency surgical treatment preferably within the first $48 \mathrm{hr}$ (Garrett and Rhamy, 1966; Ellis, 1974) offers a good chance of halting the destructive changes taking place in the corpora carvernosa thereby averting the misfortune of impotence. Two unusual cases of this condition are herein presented. The first was idiopathic in origin and had lasted for 7 days. An initial bilateral carverno-spongiosum shunt produced an indifferent result. Following a right caverno-saphenous anastomosis 14 days later, however, detumescence, pain relief and a partial return of potency was achieved. The second case, due to sickle cell anaemia, had had a caverno-spongiosum shunt performed with little improvement. A caverno-saphenous shunt established 5 days later led to recovery of potency.

\section{Case reports}

Case 1

A 25-year-old farmer presented with a 6-day history of priapism. He stated that erection had occurred soon after passing urine on waking up in the morning. He had had no previous episode. His previous medical history was unrevealing. He was married and had a 3-year-old son. Systematic enquiry elicited no significant information.

Examination revealed a fit young man in considerable distress. Temperature was $37^{\circ} \mathrm{C}$; pulse, $82 / \mathrm{min}$, regular; BP, $120 / 80 \mathrm{mmHg}$; PCV, $38 \%$. The penis was strongly erect, warm and very tender. The corcorpora cavernosa were stony hard. Conservative treatment with sedation, ice packs, analgesics and heparin was instituted for $24 \mathrm{hr}$ with poor results. Emergency surgery was decided upon. Under epio dural anaesthesia, the patient was placed in the lithotomy position. After incision and evacuation of $\overrightarrow{6}$ the dark oily sludge from the cavernosa, complete detumescence was achieved. A bilateral cavernos spongiosum anastomosis was established. Inspection $48 \mathrm{hr}$ later revealed only $20 \%$ flaccidity. Further inspection after $96 \mathrm{hr}$ did not demonstrate any improvement. A decision to observe the patient for a few days was reached. Further improvement was minimal. The organ was now noted still to be painful, turgid and woody in appearance. Re-operation to establish a caverno-saphenous shunt was undertaken 14 days after the first operation.

A vertical incision, approximately $15 \mathrm{~cm}$ long was made in the right groin in the line of the long saphenous vein. By a combination of blunt and sharp dissection, this vein was explored, freed and its tributaries ligatured. A suitable length, approximately $12 \mathrm{~cm}$, was mobilized, irrigated with heparinized saline and swung medially through a subcutaneous tunnel to the base of the penis. Here another incision was made to expose Buck's fascia. This was incised to evacuate more of the grumous $N$ oily material to achieve flaccidity. A caverno-saphen- $N$ ous shunt using a double-ended $5 / 0$ atraumatic silk N suture on a $16 \mathrm{~mm}$ needle was then established. Patency of the shunt was confirmed by squeezing the penis whereupon the saphenous vein was seen

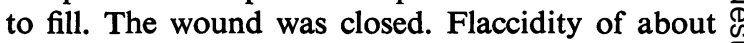
$60 \%$ was maintained. With a $14 \mathrm{~F}$. Foley urethral catheter in situ, a tight wet crepe bandage was applied. After $48 \mathrm{hr}$, detumescence was estimated at $80 \%$ and 
there was complete pain reiief. By the 6th postoperative day, the organ was no more than approximately $10 \%$ larger than normal. Out-patient follow-up showed continued improvement, and by the 3rd month, the patient claimed that he was capable of partial erections.

\section{Case 2}

A 26-year-old man, known to have sickle-cell haemoglobinopathy presented with a 48-hr history of priapism of sudden onset. He had had 2 previous episodes each of 2-3 hr duration. He had had several sickle-cell crises and had suffered an attack of infective hepatitis 6 months earlier. Examination revealed a young man, small for his age, in considerable distress. Temperature was $37 \cdot 5^{\circ} \mathrm{C}$. The $\mathrm{PCV}$ was $32 \%$, WBC, $11.9 \times 10^{\circ} / 1$. The genotype was HbSS. The urine microscopy and culture showed normal findings. The liver function tests were normal as was the chest X-ray.

The penis was strongly erect and tender, and palpation confirmed that the hardness was confined to the corpora cavernosa only. Rectal examination was normal.

Conservative treatment with sedation, ice-packs, and analgesics were tried with little effect. A bilateral caverno-spongiosum shunt was then performed but the immediate result was not impressive. Observation over the next few days produced no obvious improvement with persistence of turgidity and pain. Five days after the caverno-spongiosum shunt, a right caverno-saphenous shunt operation was undertaken.

Dark oily sludge was massaged out of the penis whereupon the organ became semi-flaccid. Irrigation with heparinized saline maintained the semi-flaccidity and this persisted until his discharge 2 weeks later. About 6 months after operation, the patient admitted to fairly normal erections and expressed satisfaction at his progress.

\section{Discussion}

The first reported description of priapism was probably that by Tripe (1885). Hinman (1914) showed early interest in the condition, collecting and describing 170 cases from the literature. But it is to Ercolani in 1869 (Hinman, 1960; Stieve, 1930; Conti, 1952) that credit goes for extending the fundamental observations of de-Graaf (Hinman, 1960) who had shown in 1668 that erection in the cadaver could be obtained by injecting water into the dorsal artery of the penis. Stieve noted the presence of longitudinal muscular pillars or cushions in the walls of vessels supplying the cavernosa. Confirmation, however, was to await the histological demonstrations of Conti who studied the penis of 20 normal individuals and showed that it was the differential

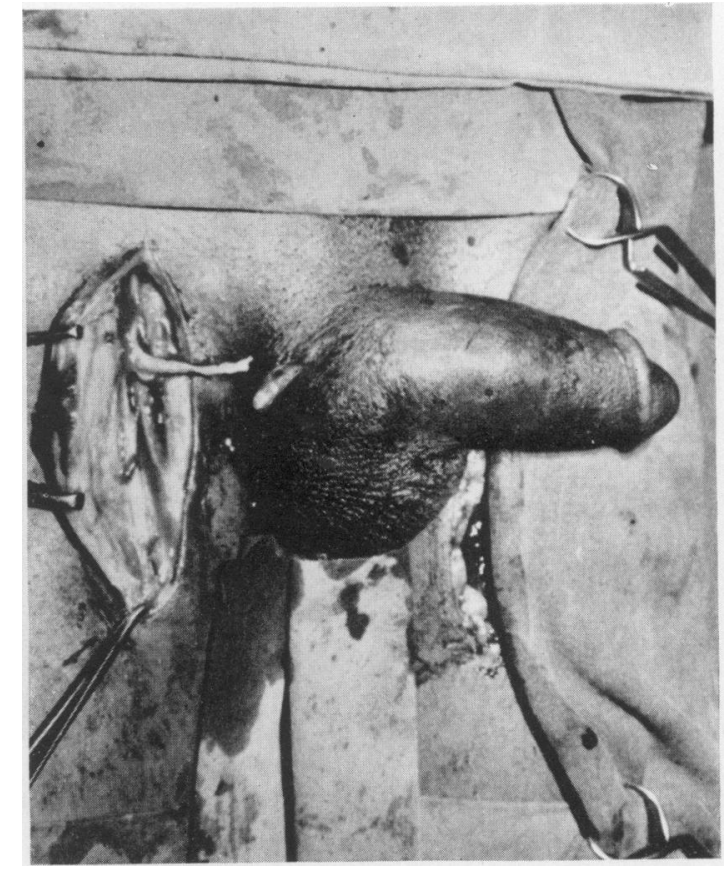

FIG. 1. The right long saphenous vein is dissected free and swung medially to the base of the penis preparatory to passage through subcutaneous tunnel.

contraction and relaxation of these muscular cushions following upon parasympathetic influences reaching them via $\mathrm{S}_{2}-\mathrm{S}_{4}$ (Henderson and Roepke, 1933) which caused filling and emptying of the lacunae of the corpora cavernosa, thereby producing erection or detumescence.

Failure of relaxation of the muscular cushions within the arterioles with contraction of those in venules and $\mathrm{A}-\mathrm{V}$ shunts led to continued arterial blood input into the cavernous sinuses, thereby maintaining the erections. Stasis of the blood in the sinuses caused biochemical and haemodynamic changes within it (Chauvin, 1938; Cuccioli, 1944). Thus the anoxia within the cavernous sinuses led to increased permeability of the vessel walls, so that fluid was lost from them. The increased viscosity (Cuccioli, 1944) led to further stasis, thereby perpetuating the erection. Organization of the 'pseudothrombosis' within the sinuses as well as the oedematous changes and fibrosis in the trabeculae produce irreversible changes in the corpora cavernosa so that only a woody, fibrotic impotent organ remains.

Various factors contributing to the initiation of priapism have been identified. The classification by Becker and Mitchell (1965), itself an extension of Hinman's (1960) earlier study, is comprehensive and useful in the understanding of the pathophysiology 


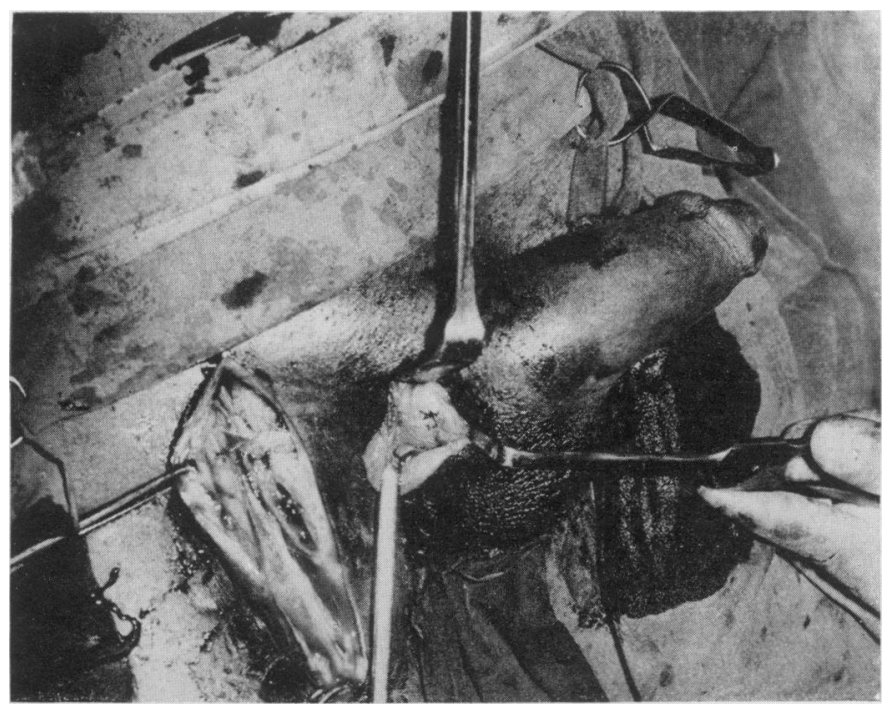

FIG. 2. Completed right caverno-saphenous shunt.

of the condition. Neurogenic lesions: psychic, tabetic, cerebral and cord; drugs: aphrodisiac mixtures, e.g. cantharides, yohimbine; mechanical lesions: perineal trauma, leukaemic infiltrations and neoplasms of the penis are rare. The haemoglobinopathies, including sickle-cell anaemia, are more common and account for about $25 \%$ of all cases (Becker and Mitchell, 1965). The commonest, worldwide, is the idiopathic type in which no predisposing factor is identifiable. This forms approximately $55 \%$ of all cases (Becker and Mitchell, 1965).

The last 50 years have seen several lines of surgical treatment advocated by various workers. Proponents of each method have claimed varying degrees of success although a careful appraisal of these methods by other workers yields results which are either poor or indifferent. These treatment modalities have included:-

(1) Large bore needle aspiration and irrigation of the corpora cavernosa with heparinized saline (McKay and Colston, 1928).

(2) Ligation of the internal pudendal artery (Burt, Shirmer and Scott, 1960).

(3) Caverno-spongiosum shunt (Quackels, 1964).

(4) Caverno-saphenous shunt (Grayhack et al., 1964).

Successful treatment of this condition aims at preventing the organization of the pseudothrombosis. Herein lies the rationale for early decompression of the cavernosa and a shunt operation. Conservative treatment with sedation, cold compresses, heparin, anaesthesia (general, spinal, epidural, caudal) and stilboestrol, are ineffective and serve only to delays definitive therapy. Of 21 patients treated conserva을 tively and studied by Grace and Winter (1968), onl 5 . 5 were judged successful. Farrer and Goodwin (1961) recorded various degrees of impotence in 14 of 15 so treated, while Hinman (1960) estimated a failure rate of $71 \%$ ( 5 of 7 ) treated by aspiration and irrigation.

The operation of caverno-saphenous anastomosis after the manner of Grayhack and his colleagues (Grayhack et al., 1964; Garrett and Rhamy, 1966; Martin, Shapiro and Buckholder, 1969) allows draining of the cavernosa of their contained dark grumous material and enables a temporary drainage shunt to maintain detumescence and prevent destructive changes taking place in the corpora cavernosa.

In Ibadan, as a first line of surgical treatment, the caverno-spongiosum shunt (Quackels, 1964; Sakatoku et al., 1968) is preferred, for the distal parts of the long saphenous vein are usually observed to be involved in the chronic lymphadenitis of the region, with consequent fibrosis, narrowing and sometimes loss of patency of this vessel.

Successful treatment in these cases was perhaps fortuitious but the operation has its adherents and in many instances, good results have been reported (Garrett and Rhamy, 1966; Foley and De Jode, 1975).

The most unusual aspect of these cases was the time interval between the onset of the priapism and the second operation. In the first case, operation had been performed 7 days after the initial symptoms 
with indifferent result. Detumescence was estimated at only $20 \%$, the oedematous woody organ remaining as painful as before. The caverno-saphenous shunt performed 14 days later achieved immediate detumescence and significant pain relief. Partial potency was achieved over the next 3 months. Although the period of priapism was not so long in the second case, re-operation was performed 7 days after its onset. Many workers (Hinman, 1960: Howe et al., 1969; Medeiros and Carvalho, 1973) have reported loss of potency after 6 or more days of priapism, although some claim residual potency only at the base of the organ, allowing intromission to occur. That truly normal erections are ever regained after prolonged tumescence is a rare occurrence. Of 5 cases of priapism treated by Garrett and Rhamy (1966) potency was recorded in $40 \%$ in all of which the priapism had lasted not more than $48 \mathrm{hr}$. In the series reported by Martin et al. (1969), potency was regained by 2 patients whose priapism had lasted one and 3 days respectively and lost by one who had been afflicted 6 days earlier.

The need for emergency surgery in the treatment of this condition is thus not in doubt. Early operation to drain the dark, oily, grumous material from the corpora cavernosa and establish a caverno-saphencus shunt would seem to be crucial to return of potency. It is advised that failure of the initial surgical operation calls for early re-operation to establish a new shunt, and that the heaviest responsibility rests upon the attending clinician.

\section{References}

Becker, L.E. \& Mitchell, A.D. (1965) Priapism. Surgical Clinics of North American, 45, 1523.

Burt, F.B., Shirmer, H.K. \& ScotT, W.W. (1960) A new concept in the management of priapism. Journal of Urology, 83, 60.

Chauvin, E. (1938) Quelques considerations sur la pathogénie du priapisme; à propos de deux cas personnels. Journal d'urologie, 46, 224.
Contı, G. (1952) L'érection du pénis humain et ses bases morphologicovasculaires. Acta anatomica, 14, 217.

Cuccioli, U. (1944) Contributo allo studio del priapismo cosidetto idiopatico. Archivio italiano di urologia, 21, 52.

Ellis, H. (1974) Annual review of surgery. Postgraduate Medical Journal, 50, 401.

FARRER, J.F. \& GooDwIN, W.E. (1961) Treatment of priapism. Comparisons of methods in fifteen cases. Journal of Urology, 86, 768.

Foley, R.J.E. \& DE Jode, L.R. (1975) The treatment of priapism by corpus-saphenous by-pass. Postgraduate Medical Journal, 51, 42.

Garrett, R.A. \& Rhamy, D.E. (1966) Priapism. Management with corpus saphenous shunt. Journal of Urology, 95, 65.

Grace, D.A. \& Winter, C.C. (1968) Priapism. An appraisal of managment of twenty-three patients. Journal of Urology, 99, 301.

Grayhack, J.T., McCullough, W., O'Connor Jr, V.J. \& TripPEL, O. (1964) Venous by-pass to control priapism. Investigative Urology, 1, 509.

HENDERSON, V.E. \& ROEPKE, M.H. (1933) On mechanism of erection. American Journal of Physiology, 106, 441.

Hinman, F. (1914) Priapism. Report of cases and a clinical study of the literature with reference to pathogenesis and surgical treatment. Annals of Surgery, 60, 689.

Hinman, Jr, F. (1969) Priapism: reasons for failure of therapy. Journal of Urology, 83, 420.

Howe, G.E., Prentiss, R.J., Cole, J.W. \& Masters, R.H. (1969) Priapism: A surgical emergency. Journal of Urology, 101, 576.

McKay, R.W. \& Colston, J.A.C. (1928) Priapism. A new method of treatment. Journal of Urology, 19, 121.

Martin, D.C., Shapiro, A. \& Buckholder, G. (1969) Corpus cavernosum saphenous vein anastomosis for priapism. Journal of Urology, 102, 221.

Medeiros, A.S. \& Carvalho, R.M. (1973) Bilateral cavernosaphenous shunt for priapism. British Journal of Urology, 45, 545.

QuACKels, R. (1964) Cure d'un cas de priapisme par anastomose caverno-spongieuse. Acta urologica belgica, 32, 5.

Sakatoku, J., Okita, J., Takaro, M. \& Koganemaru, T. (1968) Caverno-spongiosa anastomosis for relief of iodipathic priapism. Acta urologica japonica, 14, 819.

StIEVE, H. (1930) In: Handbuch der mikroskopischen Anatomie des Menschen. 712 (Ed by Mollendorf, W.), p. 327. Springer: Berlin.

TRIPE, J.W. (1845) Priapism. Lancet, ii, 8. 